\title{
Effect of intrajejunal elemental diet perfusion on jejunal secretion of immunoglobulins, albumin, and hyaluronan in man
}

\author{
J F Colombel, J P Vaerman, R Hällgren, J P Dehennin, E Wain, R Modigliani, A Cortot
}

\begin{abstract}
The aim of this work was to study the jejunal secretion of immunoglobulins (Ig), albumin, and hyaluronan in response to jejunal perfusion of an elemental diet. A four lumen tube with a proximal occluding balloon at the angle of Treitz was used for jejunal perfusion in seven healthy volunteers (mean age 23 years). The length of the test segment was $40 \mathrm{~cm}$. The jejunum was successively perfused with a control electrolyte solution for 80 minutes and with an elemental diet (containing $20.5 \mathrm{~g} / 1$ of free amino acids and $104.2 \mathrm{~g} / \mathrm{l}$ of oligosaccharides) for 100 minutes. The jejunal fluid concentrations of albumin, IgG, monomeric IgA (m-IgA), polymeric IgA (p-IgA), IgM, secretory component, and hyaluronan were measured and their jejunal outputs calculated. Within 20 minutes of starting perfusion with the elemental diet there was a significant increase in the secretion rates of albumin (×3.3), IgG ( $\times 5)$, m-IgA (×3.7), p-IgA (×2), IgM $(\times 2)$, and secretory component $(\times 1 \cdot 6)$, but the hyaluronan secretion rate was not changed. The increase in $\mathrm{m}-\operatorname{IgA}$, p-IgA, IgM, and secretory component output suggests that intestinal perfusion of an elemental diet results in stimulation of secretory immunity. The increase in albumin and IgG output probably reflects a nutrient induced leakage from the plasma compartment.
\end{abstract}

Immunoglobulins $A$ and $M$ (IgA and $\operatorname{Ig} M$ ) are the main secretory Ig in the normal adult intestine. They are transported through the

TABLE I Composition of the elemental diet

\begin{tabular}{lll}
\hline $\begin{array}{l}\text { Amino acids }(20.489 \mathrm{~g} / \mathrm{l}): \\
\text { Essential amino acids }(\mathrm{g} / \mathrm{l})\end{array}$ & L isoleucine & 1.537 \\
& L leucine & 2.09 \\
& L lysine & 1 \\
& L méthionine & 0.994 \\
& L phénylalanine & 1.23 \\
& L thréonine & 1.025 \\
& L tryptophan & 0.359 \\
& L valine & 1.914 \\
Total & & $10 \cdot 446$ \\
Non-essential amino acids $(\mathrm{g} / \mathrm{l})$ & L alanine & 1.507 \\
& L arginine & 1.435 \\
& L aspartate & 0.984 \\
& L citrulline & 0.277 \\
& L cystéine & $0 \cdot 11$ \\
& L glutamate & 0.994 \\
& Glycine & 1.271 \\
& L histidine & 0.564 \\
& L ornithine & 0.359 \\
& L proline & 1.373 \\
& L sérine & 1.055 \\
& L tyrosine & 0.113 \\
Total & Glucose & 10.043 \\
Carbohydrates: $104 \cdot 2 \mathrm{~g} / l$ & Maltose & 6.21 \\
& Oligosaccharides & 92.7 \\
& &
\end{tabular}

enterocyte by an active mechanism involving secretory component, whereas IgG reaches the intestinal lumen by transudation. ${ }^{1-4}$ Very little is known about the factors that influence secretion of Ig into the intestinal lumen. Local antigenic stimulation, such as occurs after eating, is supposed to be a primary mechanism from which a secretory immune response is generated. ${ }^{23} \mathrm{How}$ ever, the effects of nutrients on intestinal secretion of Ig have never been directly investigated in vivo in man. We therefore studied the jejunal secretion of Ig in response to jejunal perfusion of an elemental diet using a four lumen tube with a proximal occluding balloon..$^{47}$ Our experiments gave us the opportunity to add further information on the nutrient induced protein leakage from the capillary bed/interstitial fluid to the intestinal lumen by measuring the jejunal secretion rates of albumin and hyaluronan. Albumin in the intestinal lumen was derived from plasma by passive seepage, while the appearance of hyaluronan may mainly reflect leakage from the interstitium. ${ }^{89}$

\section{Methods}

\section{SUBJECTS}

The study was carried out on seven normal volunteers aged 20-24 years, with no history of gastrointestinal disease. Informed consent was obtained from all subjects and the protocol was accepted by the ethical committee of the Medical Faculty of Lille.

\section{TEST SOLUTIONS}

The solutions used to perfuse the jejunum consisted of a physiological electrolyte control solution containing $115 \mathrm{mmol} / \mathrm{l}$ of $\mathrm{NaCl}, 10$ $\mathrm{mmol} / \mathrm{l}$ of KCl , and $35 \mathrm{mmol} / \mathrm{l}$ of mannitol and an elemental diet (Enteronutril, Roger Bellon Laboratories, Neuilly/Seine, France), the composition of which is given in Table I. Both solutions contained polyethylene glycol (PEG) $4000(1 \mathrm{~g} / \mathrm{l})$ as a dilution marker and had the same $\mathrm{pH}(6 \cdot 0)$ and osmolality (300 $\mathrm{mOsmol} / \mathrm{l})$.

\section{JEJUNAL PERFUSION}

Segmental perfusion of the jejunum was performed according to Rambaud et al, ${ }^{5}$ using a four lumen tube with a proximal occluding balloon (Fig 1). The tube was swallowed by the subject in the evening before a light dinner and the perfusion was started next morning after overnight fasting. The infusion point was located near the duodenojejunal junction under the inflated 


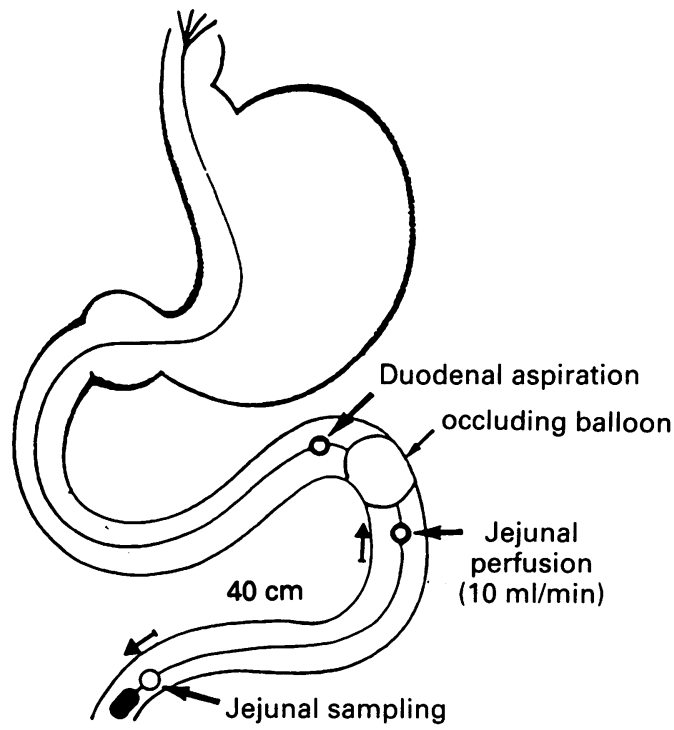

Figure 1: Four lumen tube used for segmental jejunal perfusion.

balloon (checked fluoroscopically). The gut was consecutively perfused with the control solution for 80 minutes and with the elemental diet solution for 100 minutes, at a rate of $10 \mathrm{ml} /$ minute. During the last 40 or 60 minutes of the control or the elemental diet periods respectively, two or three consecutive 20 minute samples were collected. Perfusate samples were recovered at $0^{\circ} \mathrm{C}$. Diisipropylfluorophosphate (1 $\mathrm{mmol} / \mathrm{l})$, a potent protease inhibitor, was added to an aliquot of each sample, which was stored at $-20^{\circ} \mathrm{C}$ until assayed. During perfusion, duodenal contents proximal to the balloon were continuously collected and discarded. Contamination of the jejunal samples by duodenal fluid bypassing the balloon was controlled by using two semiquantitative methods: detection of bromosulphophtalein, which was infused above the balloon into the duodenum, and detection of chymotrypsin and lipase activity in the perfusate. Any contaminated sample was discarded after detection. Absence of blood contamination

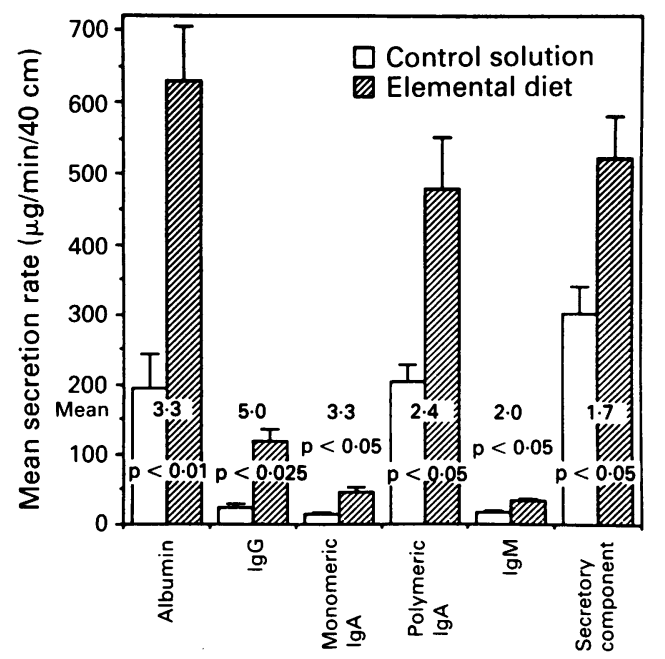

Figure 2: Mean (SEM) jejunal secretion rates of albumin, $\operatorname{Ig} G$, monomeric-IgA, polymeric-IgA, IgM, and secretory component during the perfusion of a control solution $(C)$ and of an elemental diet $(E D)$. was confirmed in all samples (Hemotest, Ames, France).

Venous blood was obtained at the beginning of experiments before intestinal perfusion, then at 50 and 70 minutes during the control period and at 10, 50,70, and 90 minutes during the elemental diet period.

\section{ANALYTICAL METHODS}

Immunoassays of proteins in serum and jejunal fluid were performed as previously described. ${ }^{4}$ Specific concentrations of albumin, IgG, IgA, and IgM in serum were measured by immunonephelometry. All proteins in jejunal samples were measured by immunoradiometric assay. Sedimentation profiles of $\operatorname{IgA}$ and secretory component in serum and jejunal fluid were analysed by sucrose density gradient ultracentrifugation, as described earlier. ${ }^{4}$ Percentages of $\mathrm{m}$-IgA and $\mathrm{p}$-IgA were measured by planimetry. Absolute concentrations of $\mathrm{m}$ - and $\mathrm{p}-\mathrm{IgA}$ were calculated from the total IgA values multiplied by the percentages determined above. Hyaluronan in perfusion fluid was measured by immunoradiometric assay (Pharmacia Diagnostics, Uppsala, Sweden). ${ }^{8}$

\section{CALCULATIONS}

The fluid flow rate at the sampling point (Frs) was calculated as follows:

$$
\text { Frs }=\text { Frp } \times(\text { PEGp }) /(\text { PEGs })
$$

where Frp is the fluid flow rate at the perfusion point, and (PEGp) and (PEGs) are the PEG concentrations at the perfusion and sampling points respectively. The secretion rate of each protein (PSR) was calculated according to the formula:

$$
\text { PSR }=\text { Frs } \times(\text { protein } s)
$$

where (protein $s$ ) is the concentration of the protein at the sampling point and was expressed as $\mu \mathrm{g} / \mathrm{minute} / 40 \mathrm{~cm}$. For each subject, values of the two samples of the control period $(\mathrm{Cl}, \mathrm{C} 2)$ and of the three samples of the elemental diet period (ED1, ED2, ED3) were averaged. Results are expressed as arithmetic means (SEM), and were compared by the Student's $t$ test for paired data.

For each subject serum values of the two samples of the control period and of the four samples of the elemental diet period were averaged.

\section{Results}

The average jejunal secretion rates during the control and elemental diet periods are given in Figure 2. When compared with the control period, perfusion of the jejunal segment with the elemental diet resulted in a $3 \cdot 3,5 \cdot 0,3 \cdot 7,2 \cdot 0,2 \cdot 0$, and 1.6 fold mean increase in albumin, IgG, $\mathrm{m}-\mathrm{IgA}, \mathrm{p}-\mathrm{IgA}, \operatorname{Ig} M$, and secretory component jejunal outputs respectively. The secretion rate of hyaluronan was unchanged during the elemental diet period compared with the control period (291 (139) $\mu \mathrm{g} / \mathrm{min} / 40 \mathrm{~cm} v 257$ (169)) (NS).

During perfusion with the elemental diet the secretion rates of albumin, $\operatorname{IgG}, \mathrm{m}-\operatorname{IgA}, \mathrm{p}-\operatorname{IgA}$, 

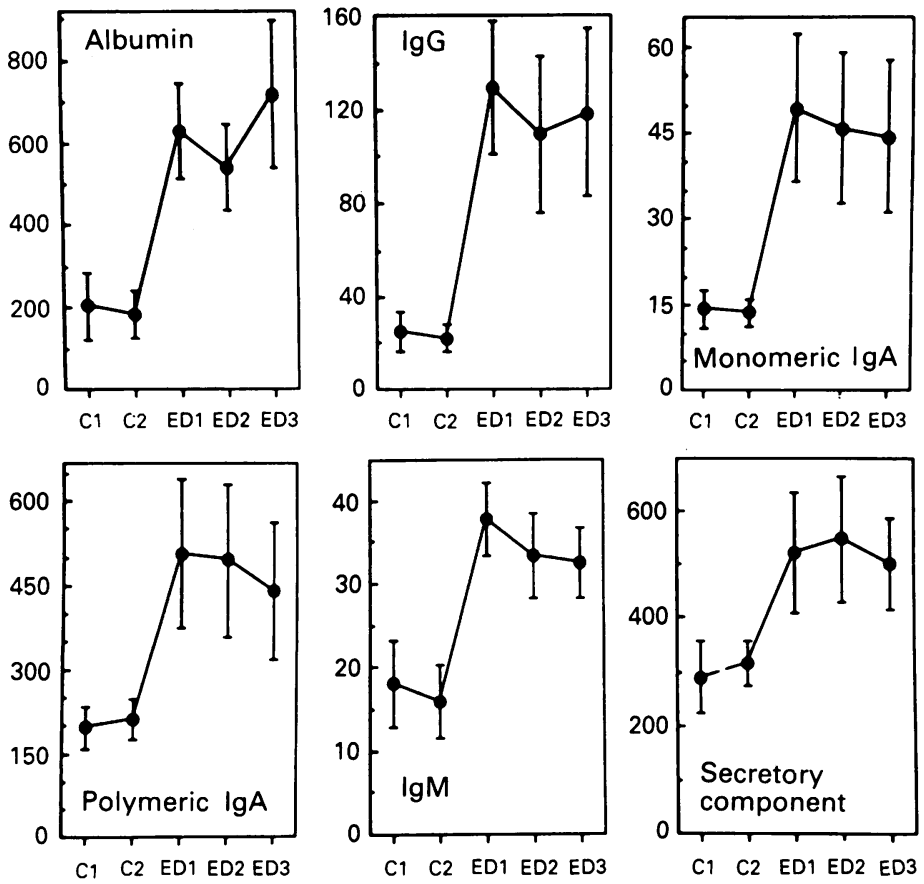

Figure 3: Mean (SEM) jejunal secretion rates of albumin, IgG, monomeric-IgA, polymericIgA, IgM, and secretory component during the two control periods $(C 1, C 2)$ and the three elemental diet periods (ED1, ED2, ED3).

IgM, and secretory component started to increase at the same time and on average 20 minutes after administration of the elemental diet (Fig 3). The secretion rates reached their maximum almost immediately and remained stable during the observation period of 60 minutes.

Serum concentrations of albumin, IgG, IgA, and IgM were identical before perfusion and during the two test periods (Table II).

\section{Discussion}

We have shown in this study that intrajejunal perfusion of an elemental diet resulted in an increase in IgA and IgM output in the jejunal lumen without concomittant changes in Ig serum concentrations. There have been no previous studies of the effect of intestinal perfusion with nutrients on intestinal secretion of $\mathrm{Ig}$ in vivo in man. In rats, intragastric instillation of food has been shown to increase secretion of IgA in a perfused isolated intestinal loop. ${ }^{10}$ The increases in jejunal output of $\operatorname{IgA}$ and IgM are probably the result of increased local production, since $98 \%$ of $\mathrm{p}$-IgA and $99 \%$ of $\operatorname{IgM}$ in jejunal secretions are derived locally from gut wall plasmacytes. ${ }^{4}$ Several mechanisms for these findings could be proposed. Firstly, a purely mechanical mechanism, namely a wash out of secretory Ig present at the epithelial surface by the bulk of nutrients, must be considered. Such a mechanism, however, might also occur during perfusion of the control solution at a similar rate. It is unlikely that a direct effect on lamina propria plasma cells by nutrients could account for the increase in Ig output. The response was too rapid for de novo synthesis and transport of the Ig. It is possible that eventually intraluminal nutrients stimulate the transcytotic transport of secretory Ig by secretory component in the
TABLE II Serum concentrations of albumin and Ig before intestinal perfusion and during the control period and elemental diet periods (values mean (SEM))

\begin{tabular}{lllll}
\hline Time & $\begin{array}{l}\text { Albumin } \\
(\mathrm{mg} / \mathrm{ml})\end{array}$ & $\begin{array}{l}\mathrm{IgA} \\
(\mathrm{mg} / \mathrm{ml})\end{array}$ & $\begin{array}{l}\mathrm{IgM} \\
(\mathrm{mg} / \mathrm{ml})\end{array}$ & $\begin{array}{l}\mathrm{IgG} \\
(\mathrm{mg} / \mathrm{ml})\end{array}$ \\
\hline Before & & & & \\
$\quad$ perfusion & $42 \cdot 5(1)$ & $1 \cdot 7(0 \cdot 2)$ & $1 \cdot 2(0 \cdot 15)$ & $12 \cdot 4(0 \cdot 45)$ \\
Control period & $40 \cdot 7(0 \cdot 8)$ & $1 \cdot 6(0 \cdot 2)$ & $1 \cdot 15(0 \cdot 15)$ & $12 \cdot 1(0 \cdot 3)$ \\
Elemental diet & $40 \cdot 7(1)$ & $1.6(0 \cdot 2)$ & $1 \cdot 15(0 \cdot 15)$ & $12 \cdot 2(0 \cdot 45)$
\end{tabular}

No significant differences between the three periods.

jejunal lumen, and the parallel increase in the secretory component secretion rate observed during the perfusion of nutrients favours this hypothesis. Thus, the perception of the arrival of nutrients into the jejunal lumen and/or their absorption into the lamina propria could act as a physiological trigger to the Ig transport system.

Our experiments add further information on the protein leakage from the capillary bed or interstitial fluid induced by the arrival of nutrients into the intestinal lumen. The perfusion of nutrients did not result in signs of increased leakage from the lymph or intestitial fluid since hyaluronan output was unchanged during nutrient perfusion. Hyaluronan, a high molecular weight glycosaminoglycan, is an important component of the interstitium and its detection in the intestinal lumen may simply reflect leakage from the interstitium. ${ }^{89}$ Conversely, the secretion rates of albumin and IgG were increased during perfusion with the elemental diet. Albumin and IgG in the intestinal lumen are mainly derived from plasma by passive seepage. ${ }^{4}$ It is reasonable to attribute their increased output to the well documented intestinal hyperaemia associated with placement of nutrients into the bowel lumen. ${ }^{11}$

In conclusion, we have shown that perfusion of an elemental diet in the jejunum induces an increase in the secretion rates of $\mathrm{Ig}$ in normal controls. The role of enteral nutrition with elemental diet in the treatment of acute Crohn's disease has been recently re-emphasised. ${ }^{12}{ }^{13}$ The mechanism of its beneficial effect is not understood, but many possibilities have been suggested including removal of food antigens, bowel rest, decreased biliary and pancreatic secretions, alteration of the faecal flora, and improved nutritional state. Our data suggest that the enteral nutrition with elemental diet could also act by increasing the jejunal secretion of Ig in the intestinal lumen, particularly the secretion of p-IgA which has recently been found to be decreased in the unaffected jejunum of patients with Crohn's disease.'

We thank C Franchisseur and J De Mets for excellent technical assistance and $M$ Lievens for kindly performing the serum immunonephelometric assays.

1 Brandtzaeg P. Role of J chain and secretory component in receptor-mediated glandular and hepatic transport of immunoglobulins in man. Scand F Immunol 1985; 22: 11146.

2 Brandtzaeg P, Sollid LM, Thrane PS, et al. Lymphoepithelial interactions in the mucosal immune system. Gut 1988; 29. interactions.

3 Brandtzaeg P, Halstensen TS, Kett K, et al. Immunobiology and immunopathology of human gut mucosa: humoral immunity and intraepithelial lymphocytes. Gastroenterology immunity and intra

4 Jonard PP, Rambaud JC, Dive C, Vaerman JP, Galian A, Delacroix DL. Secretion of immunoglobulins and plasma 
proteins from the jejunal mucosa. Transport rate and origin of polymeric immunoglobulin A. F Clin Invest 1984; 74: $525-35$.

5 Rambaud JC, Duprey F, Nouel O, Hostein J, Delpech B, Bernier JJ. Assessment of the accuracy of segmental perfusion under an occluding balloon for measuring the intrajejunal secretion of albumin and immunoglobulin. Gut 1981; 22: 371-5.

6 Colombel JF, Mascart-Lemone F, Nemeth J, Vaerman JP, Dive C, Rambaud JC. Jejunal immunoglobulin and anti-
gliadin antibody secretion in adult coeliac disease. Gut 1990; 31: 1345-9.

7 Marteau P, Colombel JF, Nemeth J, Vaerman JP, Dive C, Rambaud JC. Immunological study of histologically non involved jejunum during Crohn's disease: evidence for reduced in vivo secretion of secretory IgA. Clin Exp Immunol 1990; 80: 196-201.

8 Lavö B, Knutson L, Odlind B, Hällgren R. Signs of increased leakage over the jejunal mucosa during gliadin challenge of patients with coeliac disease. Gut 1990; 31: 153-7.

Laurent TC. Structure, function and turn-over of the extracellular matrix. In: Staub NC, Hogg JC, Hargen AR, eds. Intestinal lymphatics liquid and solute movement. Adv Microcirc 1987; 13: 15-34.

10 Freier S, Eran M, Faber J. Effect of cholecystokinin and of its antagonist, of atropine and of food on the release of immunoglobulin $A$ and immunoglobulin $G$ specific antibodies in the rat intestine. Gastroenterology 1987; 93: 1242-6.

11 Granger DN, Kvietys PR, Perry MA, Barrowman JA. The microcirculation and intestinal transport. In: Johnson LR, ed. Physiology of the gastrointestinal tract. New York: Raven Press, 1987: 1671-97.

12 O'Morain C, Segal AW, Levi AJ. Elemental diet as primary treatment of acute Crohn's disease: a controlled trial. $B M \mathcal{F}$ 1984; 288: 1859-62.

13 Giaffer MH, North G, Holdsworth CD. Controlled trial of polymeric versus elemental diet in treatment of active polymeric versus elemental diet in trea
Crohn's disease. Lancet 1990; 1: 816-9. 